\title{
Erratum to: Enhanced Tolerance to Water Deficit and Salinity Stress in Transgenic Lycium barbarum L. Plants Ectopically Expressing ATHK1, an Arabidopsis thaliana Histidine Kinase Gene
}

\author{
Ni Chen $\cdot$ Yan Liu $\cdot$ Xin Liu $\cdot$ Juan Chai $\cdot$ Zhong Hu •
}

Heng Liu

Published online: 27 January 2010

(C) Springer-Verlag 2010

Erratum to: Plant Mol Biol Rep 27(3):321-333 (2009) DOI 10.1007/s11105-008-0084-x

Prof. Guangqin Guo has not been notified of the work undertaken nor of its submission and acceptance and should not be included in the list of authors. He has not, in any way, been involved in the research and writing of this paper.

The online version of the original article can be found under http://dx. doi.org/10.1007/s11105-008-0084-x.

N. Chen $\cdot$ Y. Liu $\cdot$ X. Liu $\cdot$ J. Chai $\cdot$ H. Liu $(\bowtie)$

Institute of Cell Biology, Life Science School,

Lanzhou University,

Lanzhou 730000 Gansu, People's Republic of China

e-mail: hengliu@1zu.edu.cn

Z. Hu

Department of Biology, Shantou University,

Shantou 515063 Guangdong, People's Republic of China 